\title{
Expresión espacio-temporal del sistema de humedales de los ríos Atuel y Salado, La Pampa, Argentina
}

\author{
Hugo Ramiro Páez Campos y Pablo Fernando Dornes \\ Facultad de Ciencias Exactas y Naturales, Universidad Nacional de La Pampa. Av. \\ Uruguay 151, (6300) Santa Rosa, La Pampa, Argentina. \\ ramiropaezcampos@ hotmail.com
}

\begin{abstract}
RESUMEN
Los humedales son ecosistemas complejos y diversos, tanto en sus características biológicas como en los procesos físicos que determinan su funcionamiento. Su expresión varía por diversos factores, como el clima, la configuración geológica, la relación agua superficial-subterránea y el factor antrópico. El sistema en estudio se ubica en la confluencia de los ríos Atuel y Salado, en una región semiárida dentro de una extensa planicie aluvial conformada por numerosos cauces y bañados, cuyo régimen hidrológico se encuentra drásticamente modificado por acción antrópica, lo que dificulta la comprensión de su funcionamiento. El objetivo fue describir cambios en el patrón de inundación, a partir de teledetección con imágenes de satélite ópticas (Landsat 5 TM, 8 OLI y Sentinel 2A). Para el análisis de la variación espacial interanual y mensual, se utilizaron eventos y series continuas entre 1984-2017. El estudio de la interacción superficial-subterránea incluyó el análisis de caudales de entrada, del nivel freático y de su hidroquímica. Se observa una activación de los humedales cuya expansión y contracción está relacionada al régimen hidrológico de ambos ríos, con un carácter mayoritariamente influente. El flujo subterráneo muestra gradientes concordantes con la dirección de la escorrentía intermitente. Su ausencia determina un drástico deterioro de la calidad del agua subterránea. El patrón de inundación cambia de acuerdo a la magnitud de los eventos de escorrentía. Se visualiza que la sincronicidad de altos caudales en ambos ríos determina una mayor expresión areal y la salida de escurrimientos superficiales del sistema de humedales.
\end{abstract}

Palabras clave: Argentina, hidrogeología, humedales, superficie piezométrica, teledetección.

\section{Spatial and temporal expression of the wetlands of the Atuel and Salado rivers, La Pampa, Argentina}

\begin{abstract}
Wetlands are complex and diverse ecosystems, both in their biological characteristics and physical processes that determine their functioning. Their expression varies according to various factors, such as weather, geological environment, relationships between surface and groundwater and anthropogenic influence. The area is located at the confluence of the Atuel and Salado Rivers, in a semi-arid region within an extensive alluvial plain with many channels and flooded areas. The hydrological regime is drastically modified by upstream uses, which complicate the understanding of its functioning. The objective of the study was to describe changes in the spatial patterns of flooded areas, based on remote sensing with optical satellite images (Landsat 5 TM, 8 OLI and Sentinel 2A). For the analysis of the inter-annual and monthly spatial variation, the events and continuous series between 1984 and 2017 were used. The surface and groundwater interaction was analyzed by comparing flows, variation of the water table and hydrochemistry. The activation of the wetlands shows an expansion and contraction related to the hydrological regime of both rivers, with a predominantly influential character. Groundwater gradients have the same direction as the surface flows. The lack of these flows drastically deteriorates chemical quality of the groundwater. The flooded pattern differs according to the magnitude of the runoff events. The synchronicity of high flows in both rivers determines the area expression of the wetlands and the surface outflow from the system.
\end{abstract}

Keywords: Argentina, hydrogeology, piezometric surface, remote sensing, wetlands. 


\section{Introducción}

Los humedales son sistemas complejos, diversos y azonales. A diferencia de otros ecosistemas su existencia no se limita sólo a condiciones climáticas, sino que también es el resultado de una compleja combinación de factores geológicos, geomorfológicos, hidrológicos, y bióticos (Mitsch and Gosselink, 2015). Su dinámica depende de los procesos de retroalimentación entre estos factores, los cuales en su mayoría responden a un comportamiento no lineal (Zeff, 2012). Tradicionalmente, estos ecosistemas fueron vistos como ambientes de transición. Hoy se los considera como sistemas únicos, con posibilidad de ser abordados como objeto de estudio de forma interdisciplinaria, abarcando su estructura, funcionamiento y servicios ecosistémicos (LePage, 2011; Mitsch and Gosselink, 2015).

Los humedales ribereños poseen un funcionamiento ligado a la conectividad hidrológica entre sus componentes. Cuatro dimensiones caracterizan dicha conectividad, la longitudinal, referida a la conectividad aguas arriba-aguas abajo; la lateral, que implica las relaciones entre los cauces y los cuerpos de agua de la llanura de inundación; la vertical, que hace referencia tanto a relación agua superficial-agua subterránea como a los intercambios de masa y energía con la atmósfera y, por último, la temporal, que se refiere a los cambios a través del tiempo (Amoros et al., 1987). Esta conectividad, está condicionada por elementos estructurales y la forma en que se configuran (Schröder, 2006), ya que ambos factores influencian la probabilidad de conexión y las funciones relativas de los distintos cuerpos en la respuesta hidrológica general (Phillips et al., 2011).

Los humedales de los ríos Atuel y Salado son ribereños y de carácter epigénico. Su expresión se vincula más a los aportes alóctonos de ambos ríos que a la dinámica del agua subterránea (Dornes et al., 2016). Debido a las intervenciones antrópicas aguas arriba, ambos ríos han sido drásticamente modificados en su régimen hidrológico. El río Atuel, de régimen nival, presenta en La Pampa escorrentía intermitente y un régimen invertido, con bajos caudales en invierno y generalmente nulos en verano. El río Salado, presenta una modificación de su régimen que se manifiesta en una marcada atenuación de sus caudales y una fuerte pérdida de calidad de sus aguas (Dornes et al., 2016). El régimen modificado con aportes superficiales minimizados, determina distintas formas de expansión del sistema de acuerdo a la magnitud y al período de los eventos. Desde finales de la década del 1980, el sistema permaneció mayoritariamente inactivo salvo excepcionales eventos en los años 1998, 2001, 2007 y 2016, corroborándose la última conexión entre ambos ríos en el año 2007 (Antonena, 2017).

En base a la actual ocurrencia de escurrimientos intermitentes y minimizados que resultan en una expan- sión-contracción de los humedales de los ríos Atuel y Salado, este trabajo tiene como objetivo analizar la expresión espacio temporal del sistema de humedales, que permita determinar su estructura morfológica, describir su conectividad hidrológica y aportar a la comprensión de su hidrodinámica y su interacción con el agua subterránea, mediante el uso de teledetección y el estudio de las variables de entrada y salida.

\section{Materiales y métodos}

\section{Área de estudio}

El área de estudio comprende el sistema de humedales desarrollados en la confluencia de los ríos Atuel y Salado, en el Noroeste de la provincia de La Pampa, Argentina (Figura 1). Se inserta en la subregión geomorfológica y región hídrica de la llanura aluvial del Atuel-Salado y comprende una superficie de aproximadamente $10000 \mathrm{~km}^{2}$, localizada entre los meridianos $66^{\circ} 13^{\prime}$ y $67^{\circ} 38^{\prime} \mathrm{O}$ y entre los paralelos $36^{\circ}$ y $37^{\circ}$ $33^{\prime} \mathrm{S}$. El clima es considerado como continental árido o semiárido con una marcada estacionalidad. Para el período 1980-2015 la precipitación media anual fue de $447 \mathrm{~mm}$ y la evapotranspiración potencial de 1360 $\mathrm{mm}$. La temperatura media anual es de $15.6^{\circ} \mathrm{C}$, con una temperatura máxima y mínima media de $24.2^{\circ} \mathrm{C}$ y $6.7^{\circ} \mathrm{C}$ respectivamente (1951-1960). La vegetación está compuesta de pastizales sammófilos, arbustales perennifolios, comunidades palustres y vegetación halófita (Cano, 1980).

Geológicamente, el área se halla conformada por la Fm. Cerro Azul, sobre la cual, a finales del Pleistoceno, se desarrolló el sistema fluvial de los ríos Atuel y Salado como consecuencia del derretimiento glacial en la Cordillera de los Andes (Linares et al., 1980). Este sistema, al ver disminuida su energía, luego del derretimiento, depositó la Fm. Santa Isabel, que posteriormente y gracias a la acción eólica, redistribuyó sus arenas originando el depósito de la Fm. Meauco (Zárate et al., 2005; Giai, 2005). El paisaje actual está compuesto por médanos, planicies y cordones arenosos, intercalados con mesetas residuales generadas por acción fluvial de los ríos Atuel y Salado y la intensa acción eólica sobre la primitiva pediplanicie (Urbiztondo, 1975; Zárate et al., 2005). Los acuíferos freáticos se encuentran en las Fm. Santa Isabel y Meauco. El nivel freático es poco profundo, entre 1 y 7 $\mathrm{m}$ (Bojanich, 1979), con un tenor salino variable (2 a 16 $\mathrm{mS} / \mathrm{cm}$ ) y una tipificación hidroquímica asociada a la escorrentía superficial (Dornes et al., 2016; Giai, 2005).

\section{Metodología}

De la serie 1980-2018 de caudales medios mensuales ingresantes en los ríos Atuel (Pto. Ugalde) y Salado (Est. Sta. Isabel), de registros de aforos en distintos sitios en el área y de información histórica, se determinaron los eventos de inundación de mayor expresión. 


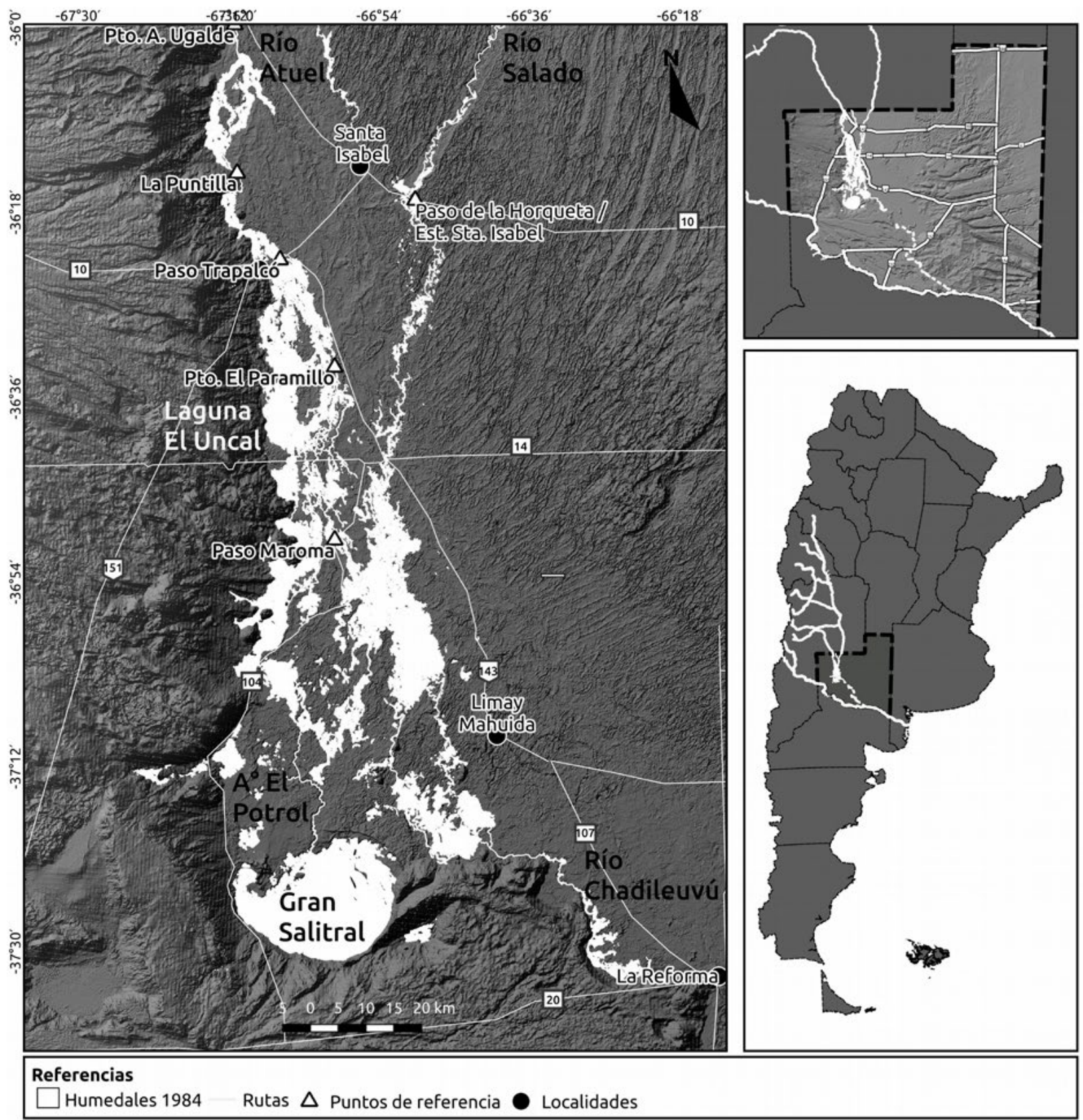

Figura 1. Humedales de los ríos Atuel y Salado en la provincia de La Pampa, Argentina. a) Ubicación del área de estudio y detalle del área inundada. b) Contexto geológico regional con litología de cobertura y principales unidades geológicas.

Figure 1. Wetlands of the Atuel and Salado Rivers, in the province of La Pampa, Argentina. a) Location of the study area and detail of the flooded area. b) Regional geological context with coverage lithology and main geological units.

Acorde a la disponibilidad de imágenes de satélite ópticas, se reconstruyó el patrón espacial de inundación en las siguientes fechas 09/1984, 07/1986, 10/1988, 09/1998, 02/2007, 09/2007, 10/2011 y 08/2016. Por otro lado, se reconstruyó, mensualmente, la serie continua de 06/2015-03/2017, con excepción de los patrones de 10/2015, 04 y 05/2016 por falta de imágenes de satélite. Este evento, de poca magnitud, se caracterizó por una expresión parcial del sistema de humedales con escorrentía continua en ambos ríos, al ingreso en la provincia de La Pampa y un caudal mensual promedio de $4.63 \mathrm{~m}^{3} / \mathrm{s}$, un máximo de $11.63 \mathrm{~m}^{3} / \mathrm{s}$ y un mínimo de $1.7 \mathrm{~m}^{3} / \mathrm{s}$ para el río Atuel. Para el río Salado el caudal mensual promedio fue de $2.58 \mathrm{~m}^{3} / \mathrm{s}$, el máximo de $12.02 \mathrm{~m}^{3} / \mathrm{s}$ y el mínimo de $0.42 \mathrm{~m}^{3} / \mathrm{s}$.

La determinación del patrón de inundación se realizó mediante la aplicación de índices espectrales. Se utilizó el índice MNDWI (Xu, 2006), el cual sustituye la ban- 
da del infrarrojo cercano (NIR) por la del infrarrojo de onda corta (SWIR) del índice NDWI (McFeeters, 1996). Ambos índices se compararon con la observación de imágenes en color verdadero y puntos de campo durante el año 2016. Se obtuvieron resultados similares, sin embargo se verificó que el índice NDWI sobreestima la cobertura de agua libre en áreas salinizadas de los cuerpos de agua, típicas en períodos de sequía. En consecuencia, se utilizaron las bandas 2 y 5 de Landsat 5 TM (Ecuación 1), las bandas 3 y 6 de Landsat 8 OLI (Ecuación 2) y las bandas 3 y 11 de Sentinel 2A (Ecuación 3). Las bandas utilizadas, correspondientes al infrarrojo, se caracterizan por una longitud de onda central cercana a los $1600 \mathrm{~nm}$. Las imágenes fueron obtenidas del portal web Earth Explorer del USGS. EI tratamiento de las imágenes y el cálculo de áreas se realizaron con el software QGIS 2.18, utilizando el sistema de referencia POSGAR 94 faja 3.

$$
M N D W I=\frac{B 2-B 5}{B 2+B 5}
$$

donde:

B2 = Banda 2 (GREEN), sensorTM, Landsat 5.

B5 = Banda 5 (SWIR), sensorTM, Landsat 5.

$$
M N D W I=\frac{B 3-B 6}{B 3+B 6}
$$

donde:

B3 = Banda 3 (GREEN), sensor OLI, Landsat 8.

$\mathrm{B} 6=$ Banda 6 (SWIR), sensor OLI, Landsat 8.

$$
M N D W I=\frac{B 3-B 11}{B 3+11}
$$

donde:

B3= Banda 3 (SWIR), sensor MSI, Sentinel 2A.

B11= Banda 11 (SWIR), sensor MSI, Sentinel 2A.

Se contrastó la evolución del área inundada de la serie 06/2015-03/2017, con los caudales medios mensuales ingresantes a los humedales. Además, se analizó la interacción agua superficial-subterránea a partir del trazado de la superficie freática y de la evaluación de la conductividad eléctrica del agua subterránea con datos de campo obtenidos durante el año 2018. La profundidad del nivel freático fue tomada con una sonda piezométrica y los valores llevados a m s.n.m. utilizando el valor de cota en boca de pozo con valores obtenidos del modelo digital de elevación TanDEM-X (Wessel, 2018), previa transformación de las alturas elipsoidales con el modelo GEOIDEAR (Piñon et al., 2017) mediante la ecuación 4. Para la obtención del valor de conductividad eléctrica se utilizó un equipo multiparamétrico portátil HANNA.

$$
H=h-N
$$

donde:
$\mathrm{H}=$ Altura ortométrica $(\mathrm{m})$

$\mathrm{h}=$ Altura elipsoidal $(\mathrm{m})$

$\mathrm{N}=$ Altura geoidal $(\mathrm{m})$

\section{Resultados y discusión}

\section{Configuración hidromorfológica del sistema de humedales}

El río Atuel ingresaba por múltiples brazos al territorio pampeano y confluía con el río Salado en un amplio frente, desde Paso de la Horqueta hasta Paso Maroma (Bojanich, 1979) (Figura 1). Esta configuración no se registra en la actualidad, debido a la drástica disminución y a la interrupción de caudales por acción antrópica aguas arriba, a excepción de la importante activación de los humedales registrada a comienzos de la década del 1980. El humedal es un ambiente aluvial de bajo gradiente con superficies de agradación de distinta antigüedad relativa (Zárate et al., 2005). Se distinguen dos sectores, el superior con dominio de geoformas aluviales canalizadas, y el terminal, que se caracteriza por la ocurrencia de áreas de derrame con escasas geoformas canalizadas.

Cuando existe escorrentía, el río Atuel ingresa por un único brazo encauzado, el Arroyo de la Barda, y conforma dos bañados, aguas arriba y aguas abajo de La Puntilla. Al sur de la localidad de Algarrobo del Águila, el cauce pierde definición y se verifica un ambiente de derrame. Luego se bifurca en dos brazos, el occidental y el oriental. Este último, recibe además aportes de desbordes de los últimos bañados de La Puntilla que cruzan la RN 151 por el Paso Trapalcó, cuando se registran grandes caudales. El brazo occidental aporta a la laguna de El Uncal, un cuerpo de $97.15 \mathrm{~km}^{2}$ en su máxima extensión. Superada la cota umbral de 288 m s.n.m., el cauce es más conspicuo y conecta depresiones al pie de la barda, conformando un sistema de lagunas encadenadas, las cuales se activan secuencialmente al verse superados los umbrales locales. En períodos sin escorrentía, las depresiones constituyen bajos hipersalinos y la última, conforma la cabecera del arroyo El Potrol que desemboca en el Gran Salitral.

El brazo oriental escurre en sentido O-E por $5 \mathrm{~km}$ y luego sigue rumbo al SE paralelo a la RN 143 con un diseño anastomosado. Luego, rumbo al SSO, alcanza el Paso Maroma donde confluye, en un diseño distributario, con bañados del río Salado. Desde este subsistema se activan en épocas de crecidas dos cursos de agua poco definidos, de dirección $\mathrm{N}-\mathrm{S}$, uno de los cuales termina por alcanzar el arroyo El Potrol.

El río Salado ingresa con un marcado diseño meándrico a La Pampa. El cauce se mantiene definido y en cercanías a la RP 14 se observan reducidos sistemas dendríticos hacia el cauce. Aguas abajo, se manifiestan bañados que conforman el nivel de base para los exiguos caudales actuales. Estos están caracterizados por un albardón en el cauce principal que determina el desa- 
rrollo de dos subsistemas de humedales paralelos al río Salado, los cuales en sus cabeceras presentan los mencionados cauces de diseño dendrítico. Sobre el subsistema occidental del Salado, se produce la confluencia con el río Atuel. Hacia el sur, el río Salado se divide en dos brazos conocidos como Paso de los Cojudos, al oeste y Paso de los Carros al este, que se alternan con bañados de menor extensión, hasta confluir en un único cauce denominado río Chadileuvú que escurre intermitentemente hacia la localidad de La Reforma.

Tanto el cauce del Arroyo de la Barda, como el río Salado en su entrada al territorio pampeano corren sobre fallas (Giai et al., 2005). Los primeros $35 \mathrm{~km}$ del río Salado en territorio pampeano atraviesan la $\mathrm{Fm}$. Meauco, la cual circunscribe su llanura de inundación (Melchor y Llambías, 2000). El Arroyo de la Barda por su parte, fluye sobre una falla N-S que limita a los afloramientos pre-terciarios exhumados del talud de erosión, ubicados al oeste de la faja aluvial. Los afloramientos y subafloramientos controlan la expresión del brazo occidental y configuran el sistema de bajos encadenados, ya que el avance hidráulico en el Atuel se da como un frente mojado mediante la saturación del subálveo (Dornes et al., 2015), y el basamento determina que la activación de los bajos ocurra secuencialmente al superar determinadas cotas umbral. De manera similar, Giai (2005) describe la presencia de basamento subaflorante en cercanías a la localidad de Limay Mahuida, el cual podría constituir un impedimento hidráulico al avance del frente mojado en el río Salado. Dicha configuración resultaría en un embalsamiento concordante con la expresión de amplios humedales inmediatamente aguas arriba. En la salida del sistema, el río Chadileuvú debe su rumbo SE al control otorgado por el paleoabanico del río Colorado y constituye el desagüe de los humedales.

Los depósitos eólicos recientes alcanzan $5 \mathrm{~m}$ de espesor y $100 \mathrm{~m}$ de longitud con sentido SO-NE (Bojanich, 1979), y condicionan el flujo superficial en el sistema. Este efecto se evidencia, sobre todo, en el patrón de inundación de los últimos bañados del río Salado, en Paso de los Carros y Paso de los Cojudos. La acción eólica se ve favorecida por la falta de escorrentía durante largos períodos. Así mismo, la dinámica de expansión y contracción de los humedales beneficia la colonización de especies arbustivas exóticas como Tamarix sp. Estos procesos afectan a la capacidad de conducción de los cauces pudiendo modificar el patrón de inundación.

\section{Dinámica espacio-temporal de los humedales}

La activación de los humedales presenta rasgos morfológicos distintos de acuerdo a la magnitud y sincronicidad de los pulsos del río Atuel y del Salado (Dornes et al., 2016 y Antonena, 2017). La expresión areal mayoritaria está asociada a la escorrentía del río Atuel. Desde 1984, la conexión de ambos ríos no se manifiesta en el amplio frente de confluencia, sino que se ha constituido en dos conexiones puntuales, una en Paso de los Algarrobos (1986 y 2001), y otra, en el extremo sur del frente de confluencia, en Paso Maroma, (1986, 1988, 1998 y 2007) (ver Figura 1). Las imágenes de satélite registran cauces resultantes de avulsiones, que podrían originarse por cambios en la pendiente o la falta de capacidad de conducción de los cauces ante grandes pulsos por obstrucción, debido al depósito de material eólico o la colonización de especies vegetales exóticas ( $T a$ marix sp.) en períodos sin escorrentía. La activación de cauces obedece en algunos casos a la superación de umbrales topográficos y en otros, a la saturación de subsistemas de bañados debida al avance de un frente mojado. Un cambio relevante entre diferentes eventos es la activación del antiguo brazo principal del Salado en 1986 y 1988, un cauce paralelo al actual cauce activo, ubicado a $7 \mathrm{~km}$ de la margen izquierda del mismo, y que se extiende hasta la localidad de Limay Mahuida. Otro fenómeno notable en este río es la activación de los humedales al sur de la RP 14 por embalsamiento y llenado de los cauces dendríticos por agua en remanso (backwater), atribuible al control del basamento subaflorante en cercanías a Limay Mahuida, que impediría el avance del frente mojado y consecuentemente resultaría en una saturación del subálveo y una mayor expresión superficial. Los relevamientos catastrales de 1880 y los relatos históricos permiten inferir una expresión del sistema aún mayor a la de los últimos eventos estudiados (desde 1984 en adelante), lo cual indica que en estos últimos la activación ha sido parcial, además de episódica. En términos generales, actualmente el sistema se encuentra drásticamente disminuido en su expresión espacial por acción antrópica aguas arriba del área (Figura 2).

El análisis del evento 06/2015-03/2017, corrobora el carácter epigénico de los humedales y la existencia de un fenómeno de expansión-contracción (Figura 3), fundamentalmente en el río Atuel. Se observa, además, la activación del río Chadileuvú en respuesta al caudal medio mensual de $12.02 \mathrm{~m}^{3} / \mathrm{s}$ del río Salado.

La Figura 4 muestra como existe una relación entre los caudales ingresantes y el área inundada que se manifiesta con un desfasaje de 4 meses en el río Atuel (Figura 4a), mientras que en el río Salado no se evidencia dicha la relación (Figura 4b).

El desfasaje temporal en el río Atuel es respuesta a los bajos caudales ingresantes, a los $45 \mathrm{~km}$ de flujo encauzado entre la estación de aforo y el área de bañados, que involucra una traslación de la onda de 30 días aproximadamente, y a la extensa área de humedales. En términos generales, se observa que es de aproximadamente 4 meses. El río Salado, por el contrario, posee una menor área de bañados asociada lateralmente y una mayor conectividad longitudinal, que determina que una vez colmado el almacenamiento de los mismos, se active el río Chadileuvú como salida del sistema. Este fenómeno, resulta en una relación me- 


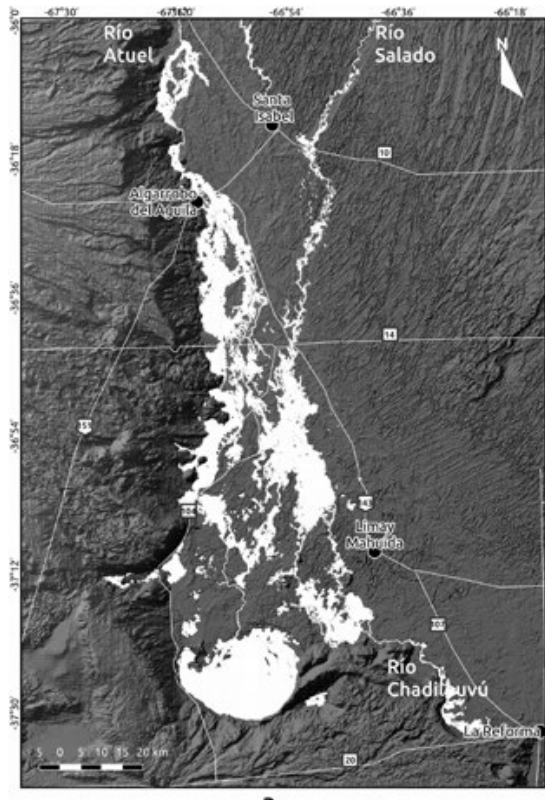

a
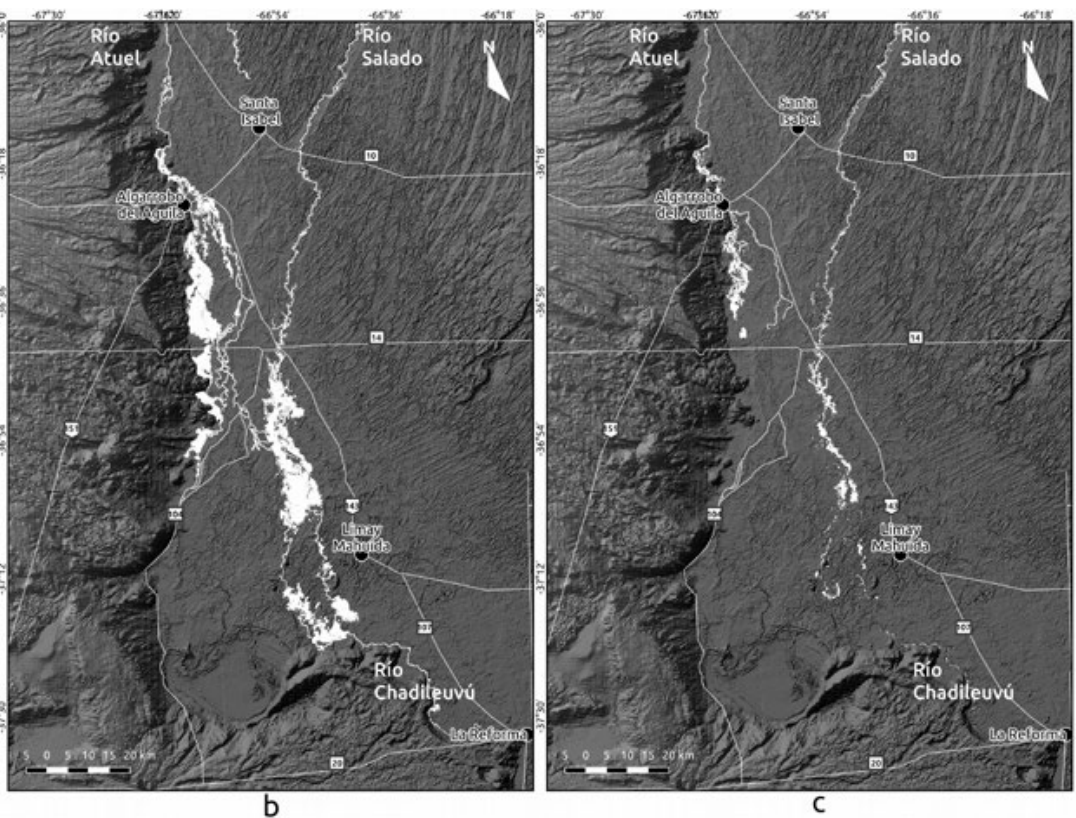

Figura 2. Evolución histórica de los humedales de los ríos Atuel y Salado.Mayor expresión (1984). b) Expresión intermedia (1998). c) Expresión minimizada (2018).

Figure 2. Historical expansion and contraction of the wetlands of the Atuel and Salado Rivers. a) Largest expression (1984). b) Intermediate expression (1998). c) Minimized expression (2018).

nos evidente entre caudales y área inundada.

Esta expansión epigénica de los humedales tiene una importante interacción con el agua subterránea, donde la recarga de los caudales eleva el nivel freático y conforma un frente mojado de avance a lo largo de la faja aluvial que va saturando progresivamente los humedales. En consecuencia, se verifica un gradiente hidráulico subterráneo NO-SE en la faja aluvial coincidente con el sentido de la escorrentía superficial (Figura 5a), y que a su vez se manifiesta en calidades químicas diferenciadas del agua subterránea entre la parte superior y terminal de los humedales (Figura
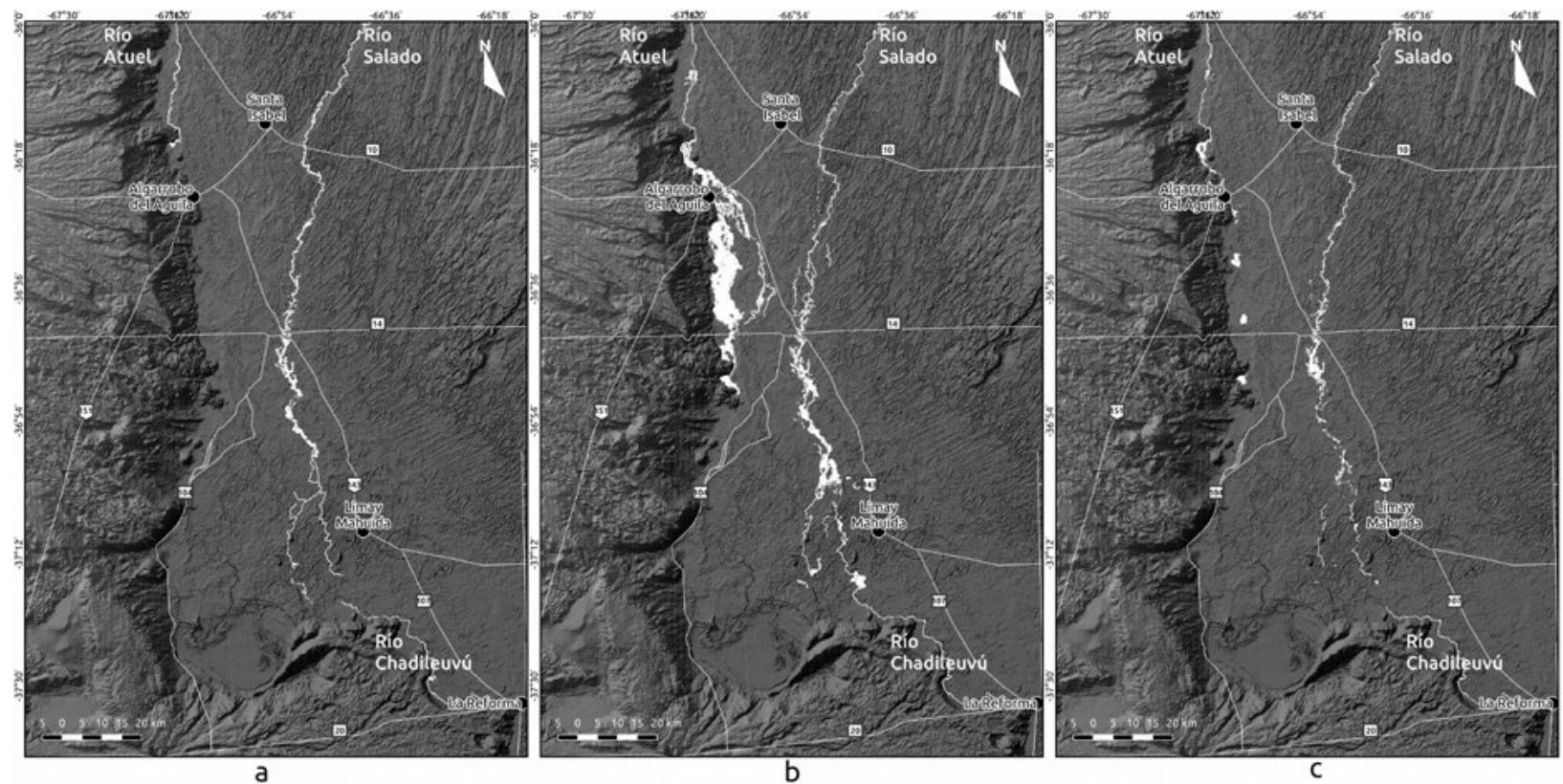

Figura 3. Expansión y contracción de los humedales de los ríos Atuel y Salado durante el evento 2015-2017. a) Fase inicial (06/2015). b) Fase de Expansión (11/2016). c) Fase de contracción (02/2017).

Figure 3. Expansion and contraction of the wetlands of the Atuel and Salado Rivers during the 2015-2017 event. a) Initial phase (06/2015). b) Expansion Phase (11/2016). c) Contraction phase (02/2017). 


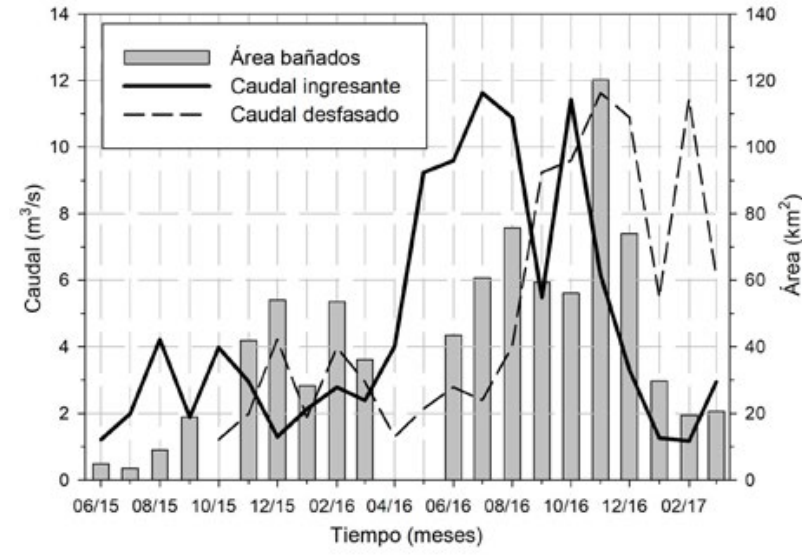

a

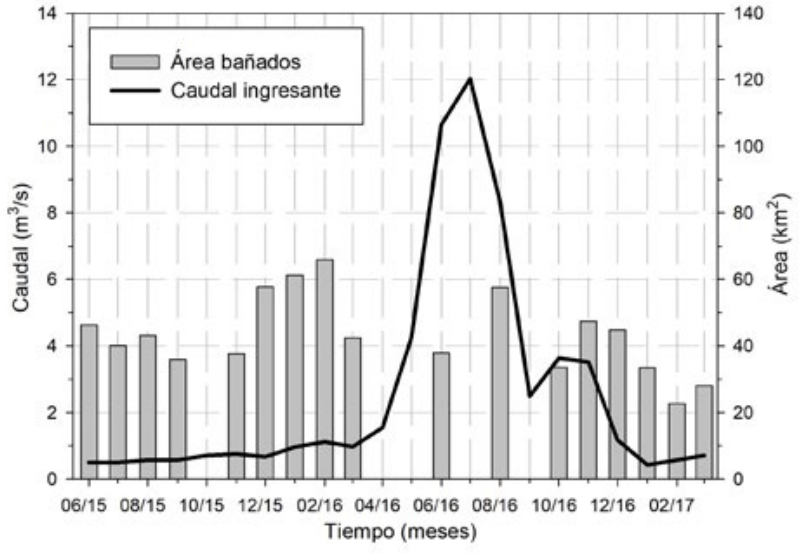

b

Figura 4. Evolución del caudal medio mensual y del área inundada para el período 06/2015 - 03/2017 en: a) Río Atuel (caudal en est. Pto Ugalde) y b) Río Salado (caudal en est. Sta Isabel). La línea punteada ilustra el caudal desfasado.

Figure 4. Evolution of average monthly flow and flooded area for the period 06/2015 - 03/2017 in: a) Atuel River (flow in Pto Ugalde gauge st.) and b) Salado River (flow in Sta Isabel gauge st.). Dotted line shows the offset flows.

5b), variando aproximadamente entre 2 y $13 \mathrm{mS} / \mathrm{cm}$ de conductividad eléctrica, respectivamente. Por otro lado, la Figura 5 b ilustra la diferencia en tenor salino existente entre el área de influencia del río Atuel y el área de influencia del río Salado. Considerando, además, el carácter relativamente más influente del Atuel sobre el agua subterránea ilustrado por la curvatura de las líneas equipotenciales, fundamentalmente en la zona superior del área de estudio.

En la parte más distal del humedal, afectada por el cese de los escurrimientos y por el predominio de procesos evaporativos, es común la presencia de cubetas de deflación y lagunas hipersalinas someras, y de agua subterránea con altos tenores salinos que imposibilitan cualquier uso. Dicha expresión, coincide con los resultados de análisis isotópicos que verifican un enriquecimiento isotópico en el sentido del escurrimiento del agua superficial y subterránea, el cual se ajusta a una recta evaporativa alejándose paulatinamente de la recta meteórica (Dornes et al., 2014).

\section{Conclusiones}

Se describe la estructura morfológica, y la conectividad hidrológica del sistema de humedales de los ríos Atuel y Salado, hoy drásticamente disminuidos en su expresión, a partir de la interpretación de imágenes de satélite seleccionadas de los últimos 34 años y datos de campo.

La estructura morfológica comprende cauces rectilíneos, meándricos y anastomosados, bañados, cuerpos de agua y redes de drenaje distributarias y dendríticas, con una mayor expresión en los humedales del río Atuel. La geología modela la estructura del brazo occidental del río Atuel. La barda define límites topográficos al curso en la margen de la faja aluvial, y los afloramientos o subafloramientos del basamen- to afectan a la conectividad hidrológica superficial y definen la existencia de un sistema de lagunas o depresiones encadenadas. El brazo oriental presenta cauces definidos y predominio de procesos avulsivos que dan lugar a redes de drenaje anastomosadas y distributarias. Estos procesos deben su origen a los cambios de pendiente en zonas de derrame y a la pérdida en la capacidad de conducción de los cauces, debido a la obstrucción por colonización de especies arbustivas exóticas y a la acción eólica favorecida en períodos sin escurrimientos.

Sobre el brazo occidental del río Atuel, el desborde de la laguna EI Uncal, la activación de cauces y el subsistema de lagunas encadenadas están controlados por la superación de umbrales. El brazo oriental del río Atuel en cambio, se desarrolla gracias a la conectividad longitudinal de cauces y bañados, y al igual que el Paso Trapalcó, los dos brazos al sur de Paso Maroma, y el antiguo cauce del Salado, se activa por la saturación de subsistemas de humedales. Tanto la saturación de bañados como la superación de umbrales dependen de la intensidad de los pulsos y la duración de los caudales.

La relación caudal-área inundada corrobora el carácter epigénico de los humedales y el fenómeno de expansión-contracción de los mismos, ligado a la drástica modificación del régimen hidrológico de ambos ríos. Esta relación es más evidente en el río Atuel, debido a la mayor conectividad hidrológica longitudinal del río Salado, como consecuencia de la menor capacidad de almacenamiento de sus humedales y su continuidad por el río Chadileuvú.

Como consecuencia de la intermitencia de los escurrimientos del río Atuel, se verifica una interacción influente, que resulta en un aporte esporádico de los flujos superficiales hacia el acuífero. Esta influencia se manifiesta en una mejora de la calidad del agua 


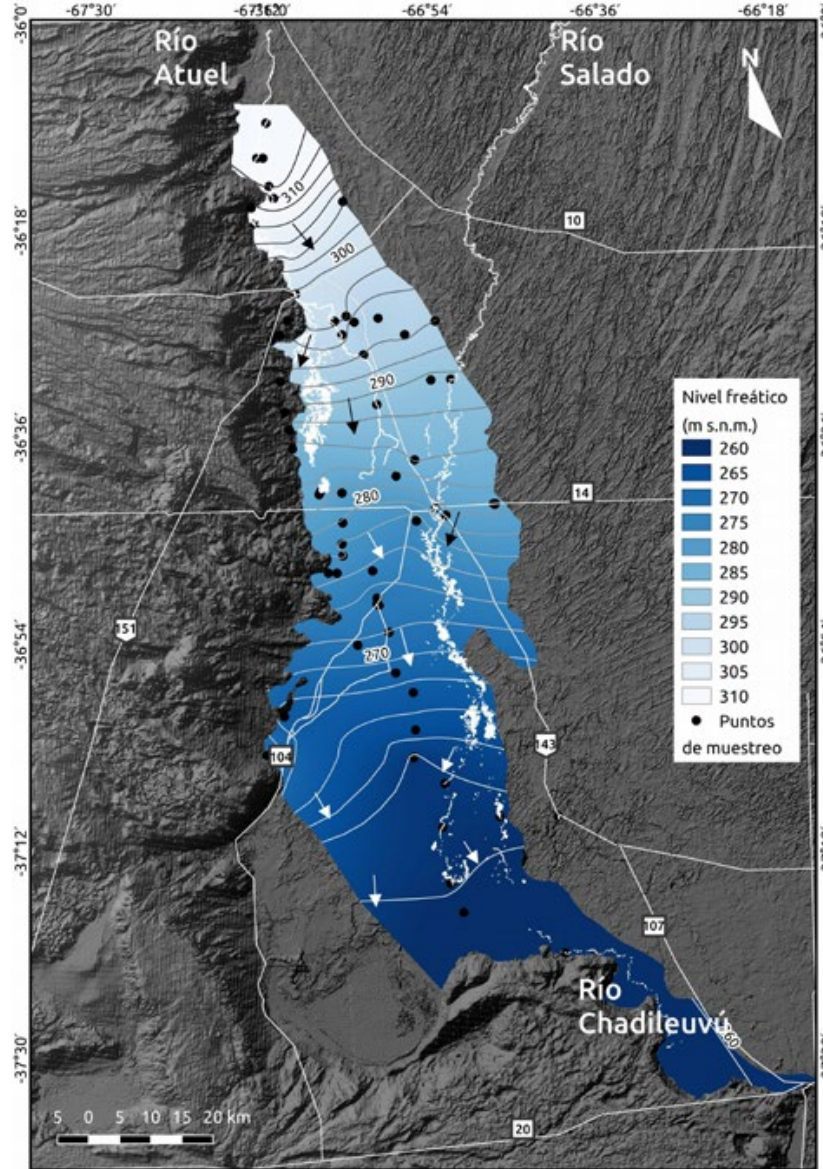

a

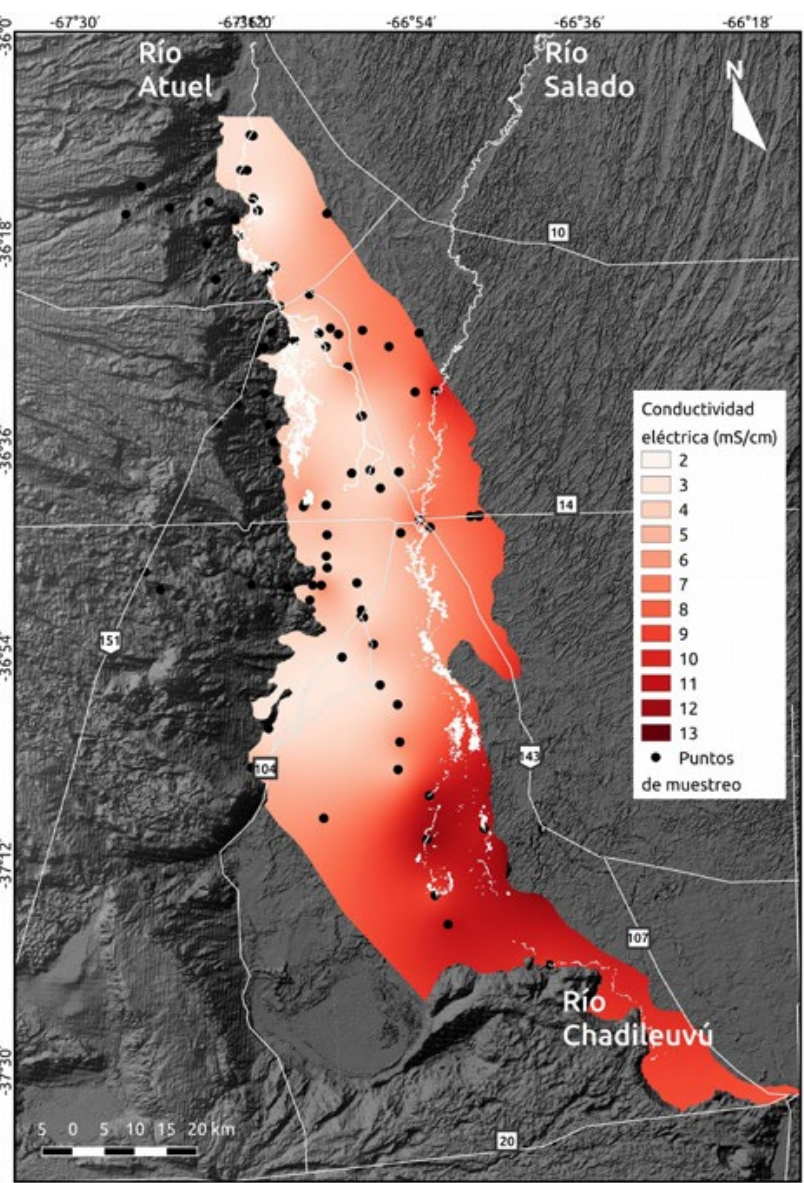

b

Figura 5. Cursos superficiales activos y bañados de los humedales de los ríos Atuel y Salado para 2018. a) Mapa de Isopiezas (m s.n.m.). b) Mapa de Isosalinidad ( $\mathrm{mS} / \mathrm{cm})$.

Figure 5. Surface active courses and flooded areas of the wetlands of the Atuel and Salado Rivers in 2018. a) Map of equipotential lines (m s.n.m.). b) Isosalinity map ( $\mathrm{mS} / \mathrm{cm}$ ).

subterránea en la llanura aluvial, lo que resulta en un beneficio para la producción ganadera local. Por otro lado, en el río Salado la relación agua superficial-subterránea presenta menores gradientes, y es posible que dependiendo de los caudales y las secciones del río esta relación alterne entre influente y efluente. EI agua subterránea en el área de influencia del río Salado presenta, para los caudales actuales, menores tenores salinos que el agua superficial y siempre mayores que en el área de influencia del río Atuel. Esta notable diferencia en el tenor salino de ambos ríos, y sus relaciones con el agua subterránea, evidencian la importancia de lograr escurrimientos permanentes que garanticen la confluencia del río Atuel y el río Salado.

La identificación de fenómenos hidrológicos como la activación secuencial a partir de la superación de umbrales, la existencia de un frente mojado de avance, la relación río-acuífero variable, la desconexión hidráulica de cuerpos de agua durante fase de contracción, etc., aportan a la comprensión del funcionamiento de un humedal ubicado en una zona semiárida, cuya expresión se encuentra drásticamente minimizada por la acción antrópica aguas arriba. Considerando la no linealidad de los procesos actuantes, su efecto sobre la salinidad del agua superficial y subterránea, y la falta de información de detalle, esta aproximación aporta a la regionalización de la metodología a otros humedales caracterizados por una conectividad hidrológica variable, y a la gestión del recurso.

\section{Referencias}

Amoros, C., Roux, A.L., Reygrobellet, J.L., Bravard, J.P. and Pautou, G. 1987. A method for applied ecological studies of fluvial hydrosystems. Regulated Rivers. 1: 17-36.

Antonena, S.V. 2017. Análisis de los procesos de activación de los bañados de la llanura aluvial de los ríos Atuel y Salado en el noroeste de la provincia de La Pampa. UNLPam. Tesis Grado.

Bojanich, E. 1979. Investigación de los aspectos geológicos, geomorfológicos e hidrogeológicos sobre la cuenca de los ríos Atuel-Salado-Chadileuvú. APA, 
DRH. Informe inédito. Santa Rosa, 188.

Cano, E. 1980. Inventario Integrado de los Recursos Naturales de La Pampa. INTA, Provincia de La Pampa, UNLPam. Buenos Aires, Argentina.

Dornes, P.F., Antonena, S.V., Minig, A., Comas, R.N., Schulz, C.J. y Mariño, E.E. 2016. Relación entre regímenes de escurrimiento superficiales y subterráneos en los humedales de los ríos Atuel y Salado, Provincia de La Pampa. En: Relación Agua subterránea-superficial. IX CONAHI. Catamarca, Argentina, 221-228. ISBN: 978-987-661-225-8. Catamarca.

Dornes, P.F., Pochetti, R.A., Díaz, P.E., Comas, R.N., Schulz, C.J y Mariño, E.E. 2015. Escurrimientos, infiltración y recarga en la cuenca inferior del río Atuel. Anales XXV CONAGUA. Paraná, E.R. Arg. 60. 10. ISNB: 978-987-27407-4-0.

Dornes, P.F., Dapeña, C., Mariño, E.E., yy Schulz, C.J. 2014. Análisis Hidroquímico e Isotópico de la cuenca del Río Atuel, Argentina. En: Procesos Geoquímicos Superficiales en Iberoamérica. Eds: J.E. Marcovecchio, S.E. Botté y R.H. Freije. Coord: J.F. Gallardo Lancho. Sociedad Iberoamericana de Física y Química Ambiental. pp. 149-164. ISBN: 978-84-9374376-5

Giai, S. B. 2005 “Estudio de Aguas subterráneas en la región oeste de la provincia de La Pampa". Informe Final, Tomo 1. 60. Consejo Federal de Inversiones.

Ko, B.C., Kim, H.H., and Nam, J.Y. 2015. Classification of Potential Water Bodies Using Landsat $8 \mathrm{OLI}$ and a Combination of Two Boosted Random Forest Classifiers. Sensors. 15 (6): 13763-13777.

LePage, B. 2011. Wetlands: A Multidisciplinary Perspective. En: B.A. Le Page (Ed), Wetlands: Integrating Multidisciplinary Concepts. Springer, 3-25, Philadelphia.

Linares, E., Llambías, E.J. y Latorre, C.O. 1980. Geología de la provincia de La Pampa, República Argentina, y geocronología de sus rocas metamórficas y eruptivas. Revista de la Asociación Geológica Argentina. 35:87-146

Lizuaín, A., Leanza, H.A. y Panza, J.L. 1997. Mapa Geológico de la República Argentina, escala 1: 2.500.000. Servicio Geológico Minero Argentino. Disponible en: http://repositorio.segemar.gov.ar/ handle/308849217/1509

Mc Feeters, S.K. 1996. The use of normalized difference water index (NDWI) in the delineation of open water features. International Journal of Remote Sensing. 17. 1425-1432.
Melchor, R.N. y Llambías, E. J. 2000. Descripción de la hoja geológica 3766-I "Santa Isabel" (1:250.000), provincia de La Pampa. Instituto de Geología y Recursos Minerales, Servicio Geológico Minero Argentino, Buenos Aires, 43 p. + mapa.

Mitsch W. J. and Gosselink J. G. 2015. Wetlands, 5th edition. John Wiley \& Son, Inc., 736, New Jersey, USA.

Phillips, R.W., Spence, C., and Pomeroy, J. 2011. Connectivity and runoff dynamics in heterogeneous basins. Hydrological Processes. 25, 3061- 3075.

Piñon, D.A., Zhang, K., Wu, S., and Cimbaro, S.R. 2017. A new Argentinian Gravimetric Geoid Model: GEOIDEAR. In: Freymueller J.T., Sánchez L. (eds) International Symposium on Earth and Environmental Sciences for Future Generations. International Association of Geodesy Symposia. 147, 53-62. DOI 10.1007/1345_2017_267.

Schröder, B. 2006. Pattern, process, and function in landscape ecology and catchment hydrology - how can quantitative landscape ecology support predictions in ungauged basins? Hydrological Earth Systems Sciences. 10: 967- 979.

Urbiztondo, A.M. 1975. Fotointerpretación del área de los ríos Salado y Atuel. Consejo Provincial del Agua, Ministerios de Obras Públicas de la Provincia de La Pampa. Informe inédito.

Wessel, B. 2018. "TanDEM-X Ground Segment DEM Products Specification Document". Public Document TD-GS-PS-0021, Issue 3.2, EOC, DLR, Oberpfaffenhofen, Germany,[Online]. Available: https://tandemx-science.dlr.de/

$\mathrm{Xu}, \mathrm{H} .2006$. Modification of normalised difference water index (NDWI) to enhance open water features in remotely sensed imagery. International Journal of Remote Sensing. 27 (14): 3025-3033.

Zárate, M.A., Lanzillota, R., y Mehl, A. 2005. Cuenca del río Atuel: caracterización biofísica. Aspectos geológicos y geomorfológicos. En: Gavillo Novillo, J.M, Porcel, G.H., Malán, J.M. (Eds). Estudio para la determinación del caudal mínimo necesario para el restablecimiento del sistema ecológico fluvial en el curso inferior del río Atuel. I. Final. 3. 1-7. UNLPam. Sta. Rosa.

Zeff, M. 2011. The Necessity for Multidisciplinary Approaches to Wetland Design and Adaptive Management: The Case of Wetland Channels. En: B.A. Le Page (Ed). Wetlands: Integrating Multidisciplinary Concepts. Springer, 27-34, Philadelphia. 10.1007/978-94-007-0551-7_2.

Recibido: julio 2019

Revisado: noviembre 2019

Aceptado: enero 2020

Publicado: marzo 2021 
